\title{
Modelling of PVDF/CNF Conducting Polymer Nanocomposite
}

\author{
Brijesh Prasad \\ Department of Mechanical Engineering \\ Graphic Era Deemed to be University, Dehradun, 248002, Uttarakhand, India \\ E-mail: prasadbrijesh10@gmail.com \\ ${ }^{*}$ Corresponding author \\ Siddharth Arora \\ Department of Mechanical Engineering \\ Graphic Era Deemed to be University, Dehradun, 248002, Uttarakhand, India \\ E-mail: sarora805@gmail.com

\section{Vikas Rathi} \\ Department of Electronics and Communication Engineering \\ Graphic Era Deemed to be University, Dehradun, 248002, Uttarakhand, India \\ E-mail: vikas.rth@gmail.com \\ Varij Panwar \\ Department of Electronics and Communication Engineering \\ Graphic Era Deemed to be University, Dehradun, 248002, Uttarakhand, India \\ E-mail: varijpanwarcertain@gmail.com \\ Pravin P. Patil \\ Department of Mechanical Engineering \\ Graphic Era Deemed to be University, Dehradun, 248002, Uttarakhand, India \\ E-mail: pravinppati12004@gmail.com
}

(Received July 18, 2018; Accepted March 27, 2019)

\begin{abstract}
Polymer nanocomposites are highly apricated for the sensor and actuator applications. As they are soft and flexible and can produce higher cyclic loading with good repeatability. But when conductive fillers are woven in the polymer matrix it loses flexibility and enhances the conductivity. Therefore, studying the loading behavior of the nanocomposite becomes important for determining the stability and load bearing capacity of the conducting polymer nanocomposite membranes (CPNC). Therefore, the intent was to design a flexible piezoresistive strain sensor. Finite element analysis (FEA) technique was used for investigating the deformation behavior with a change in stress and strain by applying loads of 0.4 $\mathrm{N}, 0.6 \mathrm{~N}, 0.8 \mathrm{~N}$ and $1 \mathrm{~N}$. Displacement was taken as one parameter for determining the stress intensities in CPNC local regions.
\end{abstract}

Keywords- Conducting, FEM, Modulus, Strain.

\section{Introduction}

Strain measurement is an important parameter for determining the mechanical strength of any material. The piezoresistive property shown by the Conducting polymer nano composite (CPNC) is often used for the sensor and actuator application. Strain sensors ae developed using piezoresistive material for strain sensing applications (Mason and Thurston, 1957). Previously metals such as $\mathrm{Cu}, \mathrm{Au}, \mathrm{Bi}-\mathrm{Sb}, \mathrm{Mn}$ and $\mathrm{RuO}_{2}$ were used for strain sensor applications (Rajanna and 
International Journal of Mathematical, Engineering and Management Sciences

Vol. 4, No. 3, 786-794, 2019

https://dx.doi.org/10.33889/IJMEMS.2019.4.3-061

Mohan, 1987, 1988, 1989; Tamborin et al., 1997). But due to their limitations of flexibility and stiffness, polymers were looked as the replacement material. Polymers showing conducting behavior were classified as the conducting polymers (CP), which showed the high interest of researchers for the sensor and actuator applications (Hu et al., 2011; Wang and Li, 2013; Porter et al., 2001). CP are polymer materials which allow the electric charge to flow through them when the electric field is applied. They are classified as intrinsic and extrinsic conducting polymers. Intrinsic $\mathrm{CP}$ is also known as self-conducting polymers. This type of conducting polymers have $\pi$ electrons on the backbone of the polymer chain. These $\pi$ electrons help in movement of charges when voltage is applied across the polymer membrane (Naarmann, 2000). (Example: poly (pyrrole)s (PPY), poly (3,4-ethylenedioxythiophene) (PEDOT), poly (thiophene)s (PT), polyanilines (PANI), poly (p-phenylene sulfide) (PPS)). Whereas, the extrinsic CPs are developed by infiltrating the conducting fillers such as carbon nano fiber (CNF), carbon nano tubes (CNT), carbon black (CB), graphene and its oxides (Das et al., 2000; Stankovich et al., 2006; Sun et al., 2008; Li et al., 2008) in the polymer matrix (example: poly (ethylene terephthalate), polystyrene, polypropylenes, polyamides, polyethylene's, poly(butylene terephtahate), poly(lactic acid), poly (hydroxybutyrate, poly (vinyl chloride) thermoplastic polyurethanes, and bio-polyesters) (Geng et al., 2007; Pötschke et al., 2007; Yang et al., 2007). Use of CPNC for the application of sensors and actuators are increasing interest because of their high mechanical strength and flexibility. Mechanical strength is measured in the form of modulus which is important for the repeatability and functionality of the CPNC (Gustafsson et al., 1992).

Modulus (E) is an important parameter for determining the mechanical behavior of the composite material (Shanks et al., 2010). Modulus is dependent on the orientation of fiber in the polymer matrix and is calculated by means of volume fraction (V) of polymer (PVDF) to filler (CNF). Equation (1) expresses the modulus obtained for the under ideal conditions of homogeneous distribution of filler in the polymer matrix, high binding ability of the polymer with filler elements and uniform distribution of load at the time of bending or deformation where (c) represents composite, $f$ defines the fiber and $m$ defines the matrix.

$E_{c}=V_{f} E_{f}+V_{m} E_{m}=V_{f} E_{f}+\left(1-V_{f}\right) E_{m}$

Whereas the modulus obtained in real life little different and is shown by Equation (2) consisting of less uniformity, non-uniform dispersion of fibers, voids and variation in alignment of fibers in the CPNC by solvent casting technique. This is defined by the efficiency factor $(\mathrm{g})$. The modulus is calculated by the universal tensile testing instruments at varying loading conditions. The modulus calculated in the shear mode emphasizes on the fiber matrix interface. While the flexure mode shows the combination of matrix and fiber here the upper part comes in tension and lower part in compression on bending of the CPNC membrane. It is also observed during the study that the neutral axis of the composite beam is stress free and remained unaffected.

$\mathrm{E}_{\mathrm{c}}=\mathrm{g} V_{f} E_{f}+\mathrm{V}_{\mathrm{m}} E_{m}=\mathrm{g} V_{f} E_{f}+\left(1-V_{f}\right) E_{m}$ 
International Journal of Mathematical, Engineering and Management Sciences

Vol. 4, No. 3, 786-794, 2019

https://dx.doi.org/10.33889/IJMEMS.2019.4.3-061
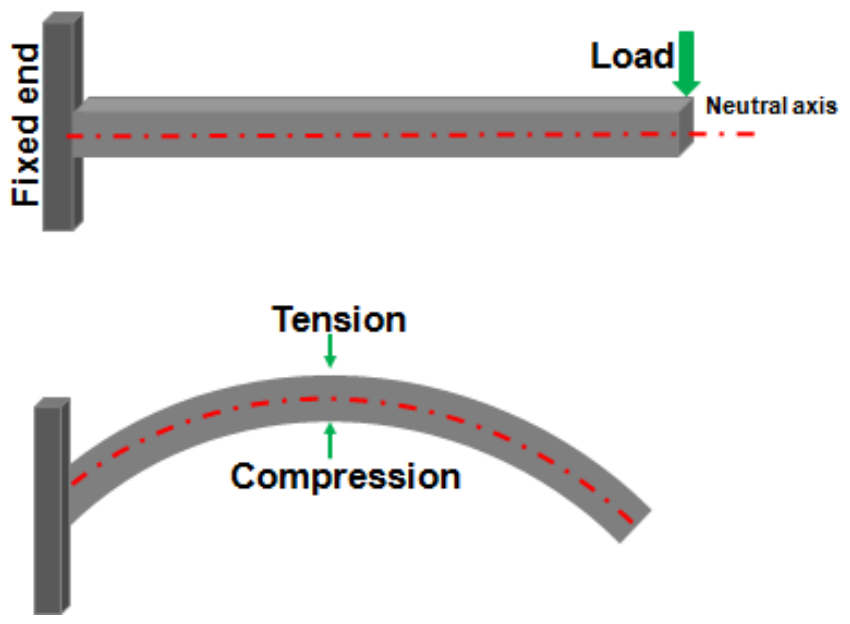

Figure 1. Represents schematic diagram of CPNC beam under load at the free end

The volume fraction of the composite is calculated using formula shown by Equation (3), where $l$ is the length of the cantilever beam $d$ is the diameter of the carbon fibers, $\mathrm{L}$ and $\mathrm{S}$ represents the longitudinal and lateral spacing of CPNC

$V_{f}=\frac{\pi \cdot l \cdot d^{2}}{4 L S^{2}}$

The geometrical fitting parameters such as area $\{\mathrm{A}=2(\mathrm{l} / \mathrm{d})\}$ of the cantilever beam for tension and $\mathrm{E}$ as the tensile Young's modulus having the aspect ratio of $(1 / \mathrm{d})$

$E_{c}=\frac{E_{m}\left(1+A B V_{f}\right)}{1-B V_{f}}$

Where B is shown by Equation (5)

$\mathrm{B}=\frac{\frac{E_{f}}{E_{m}}-1}{\frac{E_{f}}{E_{m}}+A}$

The CPNCs having conductive fillers as extrinsic component responsible for conduction reduce the yield strength in comparison to the host polymer matrix. But when added in the adequate amount it overall increases the mechanical property. When the composite is fractured the fibers embedded in the composite are pulled out and the fracture occurs in the fibers intermittently before fracturing the composite boundaries. Therefore, it is difficult to simulate the CPNCs by FEA as the composite structure does not behave uniformly and keeps changing during the rapture of the structure. Therefore, determining modulus by simulation can play a crucial role in the development of efficient electronic devices such as sensors and actuators where a minute change can make a large variation. For determining the mechanical properties some assumptions (a) The PVDF-CNF fiber matrix show perfect interface adhesion. (b) PVDF-CNF fiber matrix composite showed elastic behavior to the stress and (c) on the end of CNF fibers no axial load is transmitted were made 
International Journal of Mathematical, Engineering and Management Sciences

Vol. 4, No. 3, 786-794, 2019

https://dx.doi.org/10.33889/IJMEMS.2019.4.3-061

during the study to examine the overall behavior of the CPNC (Beckert and Lauke, 1995; Chen and Liu, 2001; Ausiello et al., 2002).

CPNC cantilever beam was designed for observing the piezoresistive sensor response. Here in the PVDF-CNF piezoresistive sensor, PVDF acted as bonding material while the CNF acted as conductive filler which helped in the charge transportation. Force was applied on the CPNC cantilever free end by applying different loads of $0.4 \mathrm{~N}, 0.6 \mathrm{~N}, 0.8 \mathrm{~N}$ and $1 \mathrm{~N}$. With the applied force resulted deformation leads to the generation of strain by changing the dimensions at the inner and outer part of the membrane finally giving rise to change in resistance. The developed CPNC is designed in the form of piezoresistive sensor showing high sensitivity and flexibility. The sensitivity of the CPNC depends on the shape, size, material and fabrication technique of the cantilever beam and is discussed in the previous work (Prasad et al., 2018). CPNC cantilever beam is simulated using the FEM software ANSYS 19.0.

\section{Sensing Characteristics Measurement of PVDF/CNF Nanocomposite}

The cantilever specimen was fixed at one end while the other end was made free. For obtaining deformation the force was applied on the free end. Different loads $(0.4 \mathrm{~N}, 0.6 \mathrm{~N}, 0.8 \mathrm{~N}$ and $1 \mathrm{~N})$ were applied at the free end. During deformation the upper part of the beam stretches, and tensile force is exerted on the upper surface of the beam as shown by Figure 1. While the lower end contracts leading to compression force at the bottom part. The obtained deformation in the form of change in strain values gives the resistance change shown by Figure 2, which can be studied in the form of electrical signals.

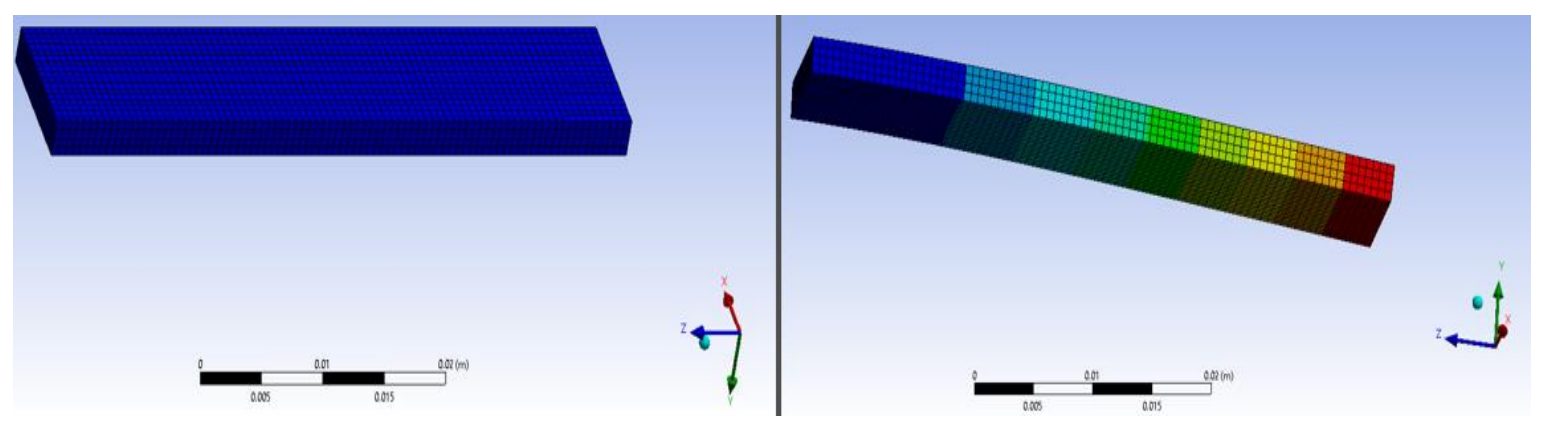

Figure 2. Represents PVDF-CNF cantilever beam without deformation and with deformation

The deflection of the CPNC is calculated using Stoney's formula and represented by Equation (6). Where $l$ is the length of the beam, E is Young's modulus, $\vartheta$ is the poison's ratio, $\sigma$ is the stress induced during deformation and $t$ is the thickness of the cantilever beam.

$\delta=\frac{3 \cdot \sigma \cdot l^{2}(1-\vartheta)}{E t^{2}}$

The displacement was observed under 0.4, 0.6, 0.8, and under $1 \mathrm{~N}$ and is shown in Figure 3. 
International Journal of Mathematical, Engineering and Management Sciences

Vol. 4, No. 3, 786-794, 2019

https://dx.doi.org/10.33889/IJMEMS.2019.4.3-061

\section{Results and Discussion}

A Finite Element Model (FEM) software ANSYS (R19.0) was used for simulation of the conductive piezoresistive sensor. The mesh of the structure was refined for a stable solution.

Figure 3(a) shows the displacement obtained on applying the load of $0.4 \mathrm{~N}$ at the top face of the cantilever beam at the free end. The minimum displacement of $1.2369 \mathrm{~mm}$ is observed at the fixed end while the maximum displacement obtained was around $11.132 \mathrm{~mm}$ at the free end.

In Figure 3(b), $0.6 \mathrm{~N}$ of the load was applied on the free end and the displacement observed was 1.8553 minimum and maximum of $16.698 \mathrm{~mm}$. when the load of $0.8 \mathrm{~N}$ was applied on the free end of PVDF/CNF nanocomposite the displace observed was 2.4737 at the fixed end and $22.263 \mathrm{~mm}$ at the free end, while the load was increased to $1 \mathrm{~N}$ the displacement observed was 3.0921 at the fixed end and $27.829 \mathrm{~mm}$ at the free end.
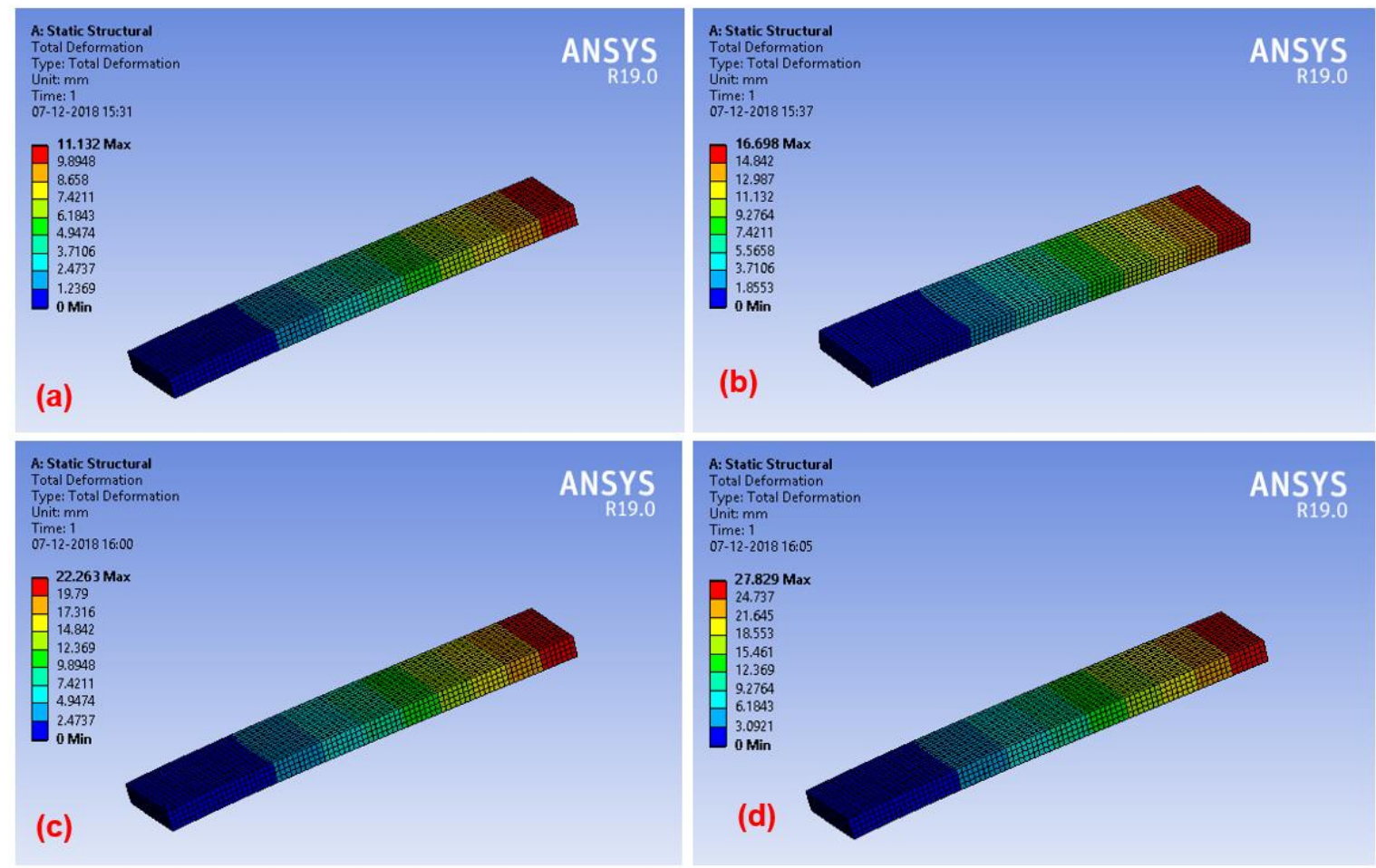

Figure 3. Represents the displacement obtained on applying (a) 0.4 , (b) 0.6 , (c) 0.8 and (d) $1 \mathrm{~N}$ load at the free end 
International Journal of Mathematical, Engineering and Management Sciences

Vol. 4, No. 3, 786-794, 2019

https://dx.doi.org/10.33889/IJMEMS.2019.4.3-061

The effect of displacement was also observed by strain produced in the cantilever beam and is shown in Figure 4, representing the equivalent elastic strain at $0.4 \mathrm{~N}$, (b) at $0.6 \mathrm{~N}$, (c) at $0.8 \mathrm{~N}$ and at $1 \mathrm{~N}$ load. The maximum strain produced on applying $0.4 \mathrm{~N}$ load is $0.02159 \mathrm{~mm} / \mathrm{min}$, for $0.6 \mathrm{~N}$ $0.032 \mathrm{~mm} / \mathrm{mm}$. Maximum strain of 0.043179 under $0.8 \mathrm{~N}$ load and 0.053974 at $1 \mathrm{~N}$. There is no major strain change when the load is varied form $0.4-1 \mathrm{~N}$. This shows the stability of the piezoresistive sensor.

The equivalent stress produced during the deformation is shown in Figure 5. Where Figure 5 (a) shows the stress obtained by applying the load of $0.4 \mathrm{~N}$, (b) shows the effect obtained by $0.6 \mathrm{~N}, 0.8$ $\mathrm{N}$ and $1 \mathrm{~N}$.
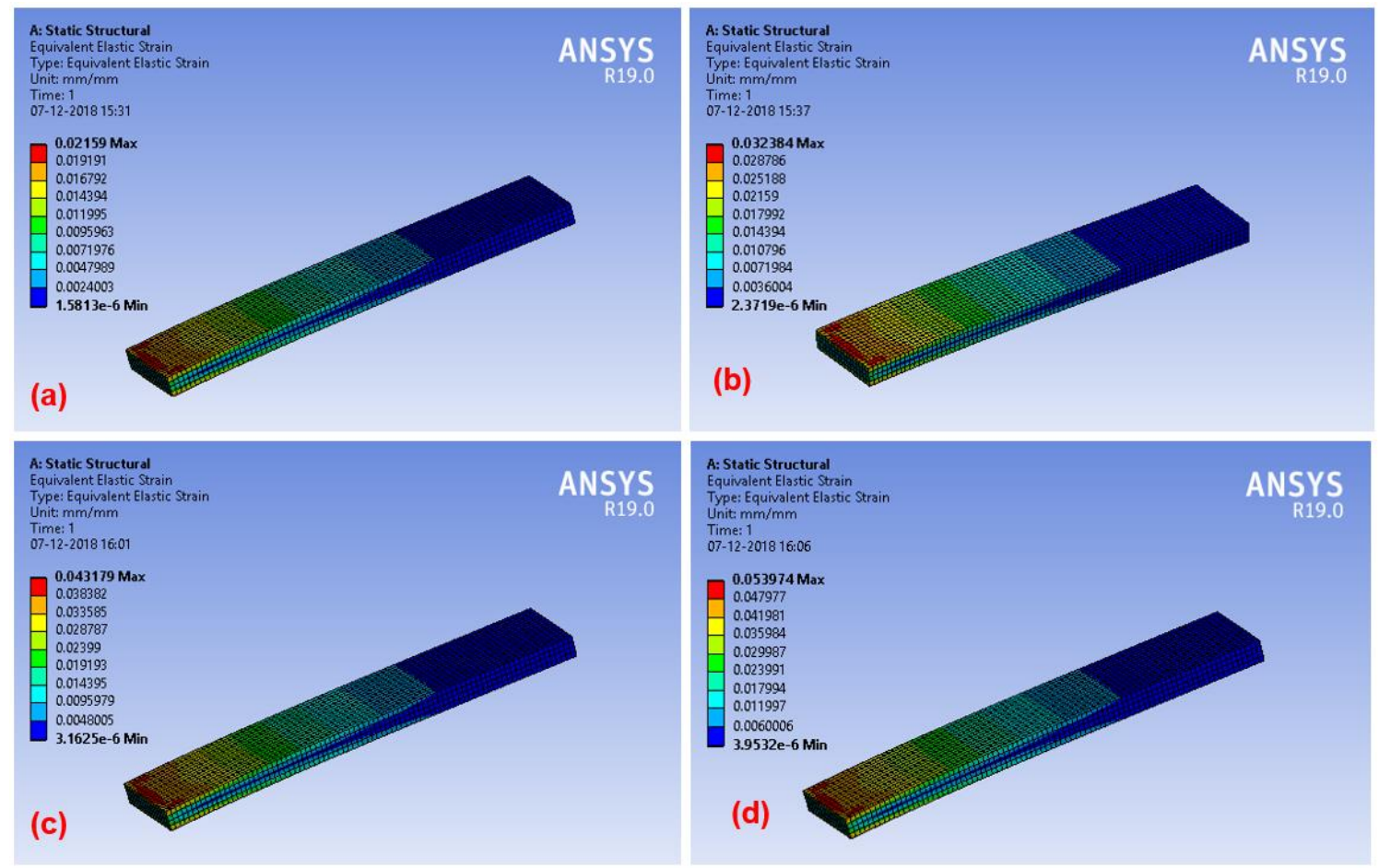

Figure 4. Represents equivalent strain obtained on applying $0.4,0.6,0.8$ and $1 \mathrm{~N}$ load at the free end 

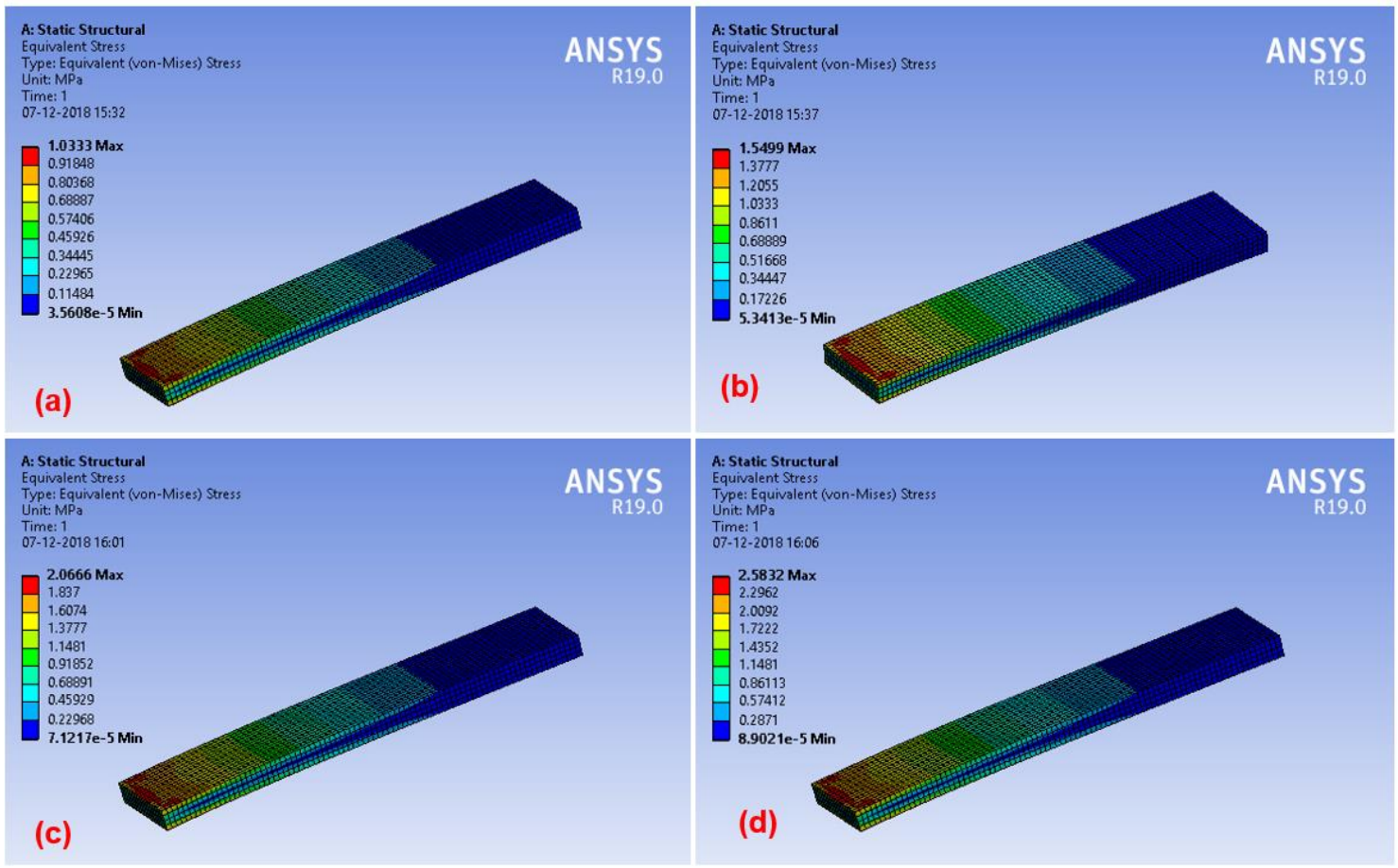

Figure 5. Represents equivalent stress obtained on applying 0.4, 0.6, 0.8 and $1 \mathrm{~N}$ load at the free end

\section{Conclusion}

CPNC are flexible polymer materials which can provide applications in electronic smart devices, sensors, actuators, human health, soft robotic arms and structural health monitoring. Piezoresistive sensors is one type of CPNC which can be applied for human health and the structural health monitoring. In human health the deformation obtained in the CPNC can be used for measuring the blood flow effect, heart beat rate and many others. While in the structural health monitoring it can be used for detecting the failure by fracture or misalignment of any crucial component. Thus, the deformation effect of the CPNC membrane is studied with the help of FEM software. CPNC Cantilever beam is designed and simulated using the ANSYS R19.0 software. The displacement behavior is analyzed under different loading conditions of $0.4,0.6,0.8$ and $1 \mathrm{~N}$. The simulation results show displacement with low stress and strain and under variable conditions. The maximum displacement of $27.829 \mathrm{~mm}$ is achieved under $1 \mathrm{~N}$ at the free ends. The strains are highest at the free ends and minimum at the fixed ends.

\section{Conflict of Interest}

All authors have contributed equally in this work. The authors declare that there is no conflict of interest for this publication. 
International Journal of Mathematical, Engineering and Management Sciences

Vol. 4, No. 3, 786-794, 2019

https://dx.doi.org/10.33889/IJMEMS.2019.4.3-061

\section{Acknowledgement}

This research is funded by Science \& Engineering Research Board (SERB) (ECR/2016/001113), Department of Science and Technology, Government of India and Graphic Era Deemed to be University, Dehradun, Uttarakhand, India.

\section{References}

Ausiello, P., Apicella, A., \& Davidson, C.L. (2002). Effect of adhesive layer properties on stress distribution in composite restorations - a 3D finite element analysis. Dental Materials, 18(4), 295-303.

Beckert, W., \& Lauke, B. (1995). Fracture mechanics finite element analysis of debonding crack extension for a single fibre pull-out specimen. Journal of materials science letters, 14(5), 333-336.

Chen, X., \& Liu, Y. (2001). Multiple-cell modeling of fiber-reinforced composites with the presence of interphases using the boundary element method. Computational Materials Science, 21(1), 86-94.

Das, N.C., Khastgir, D., Chaki, T.K., \& Chakraborty, A. (2000). Electromagnetic interference shielding effectiveness of carbon black and carbon fibre filled EVA and NR based composites. Composites part A: applied science and manufacturing, 31(10), 1069-1081.

Geng, H.Z., Kim, K.K., So, K.P., Lee, Y.S., Chang, Y., \& Lee, Y.H. (2007). Effect of acid treatment on carbon nanotube-based flexible transparent conducting films. Journal of the American Chemical Society, 129(25), 7758-7759.

Gustafsson, G., Cao, Y., Treacy, G.M., Klavetter, F., Colaneri, N., \& Heeger, A.J. (1992). Flexible lightemitting diodes made from soluble conducting polymers. Nature, 357(6378), 477-479.

Hu, N., Fukunaga, H., Atobe, S., Liu, Y., \& Li, J. (2011). Piezoresistive strain sensors made from carbon nanotubes -based polymer nanocomposites. Sensors, 11(11), 10691-10723.

Li, C., Thostenson, E.T., \& Chou, T.W. (2008). Effect of nanotube waviness on the electrical conductivity of carbon nanotube-based composites. Composites Science and Technology, 68(6), 1445-1452.

Mason, W.P., \& Thurston, R.N. (1957). Use of piezoresistive materials in the measurement of displacement, force, and torque. The Journal of the Acoustical Society of America, 29(10), 1096-1101.

Naarmann, H. (2000). Electrically Conducting Polymers. Ullmann's Encyclopedia of Industrial Chemistry, Wiley-VCH Verlag GmbH \& Co. KGaA Weinheim.

Porter, T.L., Eastman, M.P., Pace, D.L., \& Bradley, M. (2001). Sensor based on piezoresistive microcantilever technology. Sensors and Actuators A: Physical, 88(1), 47-51.

Pötschke, P., Kretzschmar, B., \& Janke, A. (2007). Use of carbon nanotube filled polycarbonate in blends with montmorillonite filled polypropylene. Composites Science and Technology, 67(5), 855-860.

Prasad, B., Panwar, V., Chaturvedi, M., Rathi, V., Gill, F.S., Sharma, K., \& Patil, P.P. (2018). Development of conductive nanocomposite for sensing application. International Journal of Engineering \& Technology, 7(3.12), 1025-1029.

Rajanna, K., \& Mohan, S. (1987). Longitudinal and transverse strain sensitivity of gold film. Journal of materials science letters, 6(9), 1027-1029.

Rajanna, K., \& Mohan, S. (1988). Studies on meandering path thin-film strain gauge. Sensors and Actuators, 15(3), 297-303.

Rajanna, K., \& Mohan, S. (1989). Strain-sensitive property of vacuum evaporated manganese films. Thin Solid Films, 172(1), 45-50. 
International Journal of Mathematical, Engineering and Management Sciences

Vol. 4, No. 3, 786-794, 2019

https://dx.doi.org/10.33889/IJMEMS.2019.4.3-061

Shanks, R. (2010). Modelling of Thermoplastic Fibre-Composites and Finite Element Simulation of Mechanical Properties. In Finite Element Analysis. (pp. 285-314) IntechOpen.

Stankovich, S., Dikin, D.A., Dommett, G.H., Kohlhaas, K.M., Zimney, E.J., Stach, E.A., Piner, R.D., Nguyen, S.T., Ruoff, R.S., \& Ruoff, R.S. (2006). Graphene-based composite materials. Nature, 442(7100), 282-286.

Sun, Y., Bao, H.D., Guo, Z.X., \& Yu, J. (2008). Modeling of the electrical percolation of mixed carbon fillers in polymer-based composites. Macromolecules, 42(1), 459-463.

Tamborin, M., Piccinini, S., Prudenziati, M., \& Morten, B. (1997). Piezoresistive properties of RuO -based $_{2}$ thick-film resistors: the effect of RuO2 grain size. Sensors and Actuators A: Physical, 58(2), 159-164.

Wang, L., \& Li, Y. (2013). A review for conductive polymer piezoresistive composites and a development of a compliant pressure transducer. IEEE Transactions on Instrumentation and Measurement, 62(2), 495-502.

Yang, B.X., Pramoda, K.P., Xu, G.Q., \& Goh, S.H. (2007). Mechanical reinforcement of polyethylene using polyethylene-grafted multiwalled carbon nanotubes. Advanced Functional Materials, 17(13), 20622069. 